\title{
Large-scale, Distributed, Multilingual, Electronic Meetings: A Pilot Study of Usability and Comprehension \\ Jamison Posey, Milam Aiken
}

University of Mississippi, School of Business Administration, University, MS 38677

jposey@bus.olemiss.edu

maiken@bus.olemiss.edu

\section{ABSTRACT}

The United Nations, the European Union, and many other organizations must conduct meetings in many languages, but typically employ human interpreters with their accompanying cost. In addition, these oral discussions require participants to take turns speaking, lengthening the process. Many studies have shown that group support systems can reduce meeting time and increase productivity, and the addition of automatic translation into this process could support these multilingual groups. However, prior studies have typically used only a few languages with group members face to face. This study investigates how well a large multilingual group can use electronic meeting software in a geographically dispersed environment. Results show that the group members were able to understand comments exchanged in 66 languages when translated to English, and they believed the multilingual meeting system was useful for such discussions.

\section{Indexing terms/Keywords}

Electronic meetings, Group Support Systems, Machine translation, Multilingual groups

\section{Academic Discipline And Sub-Disciplines}

Computer Science (machine translation)

\section{TYPE (METHOD/APPROACH)}

Survey

\section{Council for Innovative Research}

Peer Review Research Publishing System

Journal: INTERNATIONAL JOURNAL OF COMPUTERS \& TECHNOLOGY

Vol 14 . No. 3

www.ijctonline.com, editorijctonline@gmail.com 


\section{INTRODUCTION}

Several multinational organizations conduct meetings in many languages. For example, the European Union uses 24 official, working languages. The United Nations has six official languages, but other meetings could consist of more. At times, a delegate might choose to make a statement using a non-official language. Traditional, oral meetings with simultaneous translation are slow and have high costs. Therefore, relatively few international meetings are interpreted, and many instead use just one language for communication, e.g. English [18].

Electronic meetings, however, are often more productive [16]. Many group members typing and reading comments at once is more efficient than the same number taking turns speaking. In addition, most of these sessions are anonymous, allowing participants to state their true feelings. Finally, discussions are automatically transcribed in automated meetings. As a consequence, several studies have investigated the use of electronic meetings with machine translation as a substitute for oral discussions with interpretation [21]. Although translation accuracies have been poor in some cases, most of these studies have yielded promising results.

Many prior studies, with one or two exceptions, have focused on using only a few languages simultaneously. The purpose of this paper is to investigate how well a multilingual group might potentially be supported in an electronic meeting that provides automatic translation among 80 languages for participants in different locations. First, we discuss in greater detail the problems inherent in multilingual meetings, and then we review prior research on how computer-based systems have addressed these problems.

\section{LITERATURE REVIEW}

Machine translation was introduced to electronic meetings in the early 1990s [6], and since then, several studies have indicated that people can communicate efficiently and effectively in automated meetings using many different languages. Table 1 summarizes some of these studies. As indicated, comprehension has been the main problem, with rates of understanding varying from $40 \%$ to $100 \%$. However, at least one study [13] showed that understanding in a multilingual meeting with machine translation could meet the requirements for college-level English comprehension tests administered to foreign students.

Although participants in a multilingual meeting could use free, online translation such as Google Translate to understand foreign comments, studies have shown that they do not want to take the added steps and effort. For example, in one study [2], only one participant out of 21 translated nine of the foreign comments manually $(64.3 \%)$, and 11 (52.4\% of the group) did not translate any due to the extra time required (19.3 seconds on average). Even staff-supported translation is not sufficient, especially for a large meeting using many languages, as the average time to translate a comment into another language and post the resulting text back to the meeting software was about 20 seconds in the study. Automatic translation, on the other hand, can provide a translation of equivalent quality in less than half a second per language and can post the generated comments in the appropriate log. In another study [7], there was a long delay in a 40-member trilingual group between the entry of comments and the comment translation and posting by staff. At least one translation was posted incorrectly, and many of the comments were not translated at all. Thus, for all but the smallest groups, staff support for multilingual electronic meetings is not feasible [17].

Very large groups might be able to use multilingual electronic meetings. For example, in one study [9], a group of 40 people used a multilingual electronic meeting in a face-to-face environment using 40 languages, with $83 \%$ of the comments understood. In addition, using the technology, groups can meet even if members are in physically separate locations. One study [12], showed that two monolingual sub-groups communicating together as one were more satisfied with the meeting and generated more comments than a face-to-face group with the same number of participants, and another study [1] showed that larger electronic meetings composed of sub-groups generated more, unique, quality ideas per person.

Multilingual groups have also met while distributed geographically. In one meeting, four participants (one Germanspeaking, one French, and two English) in four different locations in three American states and three time zones used a Web-based meeting system with machine translation, asynchronously, to discuss Osama Bin Laden [11]. All comments were automatically translated into the appropriate language. In another meeting, five participants (two German-speaking and three English) in four locations used the Web-based system synchronously to discuss terrorism and its effect upon travel. In another study [15], a group of 32 using eight languages met synchronously in three locations. The participants thought the system was easy to use and useful, estimated that an equivalent oral meeting with a human interpreter would have taken about five times longer, and believed their comprehension of translations met the minimum standard they required. 
Table 1. Summary of select multilingual, electronic meetings (adapted [21])

\begin{tabular}{|c|c|c|}
\hline Study & Group Members & Comprehension \\
\hline 1 & 3 Spanish, 6 English & $\begin{array}{l}\text { English } \rightarrow \text { Spanish: } 96 \% \\
\text { Spanish } \rightarrow \text { English: } 85 \%\end{array}$ \\
\hline 2 & 2 Spanish, 2 English & $\begin{array}{l}\text { English } \rightarrow \text { Spanish: } 91 \% \\
\text { Spanish } \rightarrow \text { English: } 81 \%\end{array}$ \\
\hline 3 & 1 German, 1 French, 2 English & $\begin{array}{l}\text { German } \rightarrow \text { English: } 100 \% \\
\text { German } \rightarrow \text { French: } 40 \% \\
\text { French } \rightarrow \text { German: } 40 \% \\
\text { French } \rightarrow \text { English: } 60 \% \\
\text { English } \rightarrow \text { German: } 80 \% \\
\text { English- } \rightarrow \text { French: } 80 \%\end{array}$ \\
\hline 4 & 2 English, 2 Chinese & $\begin{array}{l}\text { English } \rightarrow \text { Chinese: } 93 \% \\
\text { Chinese } \rightarrow \text { English: } 100 \%\end{array}$ \\
\hline 5 & $\begin{array}{l}8 \text { pairs of Chinese, Korean, and Japanese } \\
\text { participants }\end{array}$ & $\begin{array}{l}\text { Japanese } \rightarrow \text { English: "Good" } \\
\text { Chinese } \rightarrow \text { English: "Not bad" }\end{array}$ \\
\hline 6 & $8,10,16$, and 32 English & $\begin{array}{l}\text { Hungarian, Indonesian, Latvian, } \\
\text { Lithuanian, Malay, Norwegian, } \\
\text { Swedish } \rightarrow \text { English: } 87.69 \%\end{array}$ \\
\hline 7 & 2 groups of 17 English using Asian languages & $\begin{array}{l}\text { Chinese } \rightarrow \text { English: } 59 \% \\
\text { Filipino } \rightarrow \text { English: } 72 \% \\
\text { Indonesian } \rightarrow \text { English: } 70 \% \\
\text { Japanese } \rightarrow \text { English: } 54 \% \\
\text { Korean } \rightarrow \text { English: } 45 \% \\
\text { Thai } \rightarrow \text { English: } 58 \% \\
\text { Vietnamese } \rightarrow \text { English: } 67 \%\end{array}$ \\
\hline 8 & 3 groups of 4 Korean and 11 English & $\begin{array}{l}\text { Average of Korean and English } \rightarrow \\
87.5 \%\end{array}$ \\
\hline 9 & $\begin{array}{l}\text { Groups of } 4,9,16,17 \text {, and } 25 \text { mixed Arabic, Chinese, } \\
\text { English, French, German, Hindi, Indonesian, Malay, } \\
\text { and Spanish }\end{array}$ & $\begin{array}{l}\text { Arabic: } 78 \% \text {, Chinese: } 70 \% \text {, } \\
\text { English: } 89 \% \text {, French: } 95 \% \text {, } \\
\text { German: } 65 \% \text {, Hindi: } 84 \% \text {, } \\
\text { Indonesian: } 74 \% \text {, Malay: } 90 \% \text {, } \\
\text { and Spanish: } 70 \% \text {. }\end{array}$ \\
\hline 10 & $\begin{array}{l}\text { Groups of 8, 7, 7, and } 9 \text { English using English, } \\
\text { German, Italian, Spanish, and Swedish }\end{array}$ & $\begin{array}{l}\text { German, Italian, Spanish, and } \\
\text { Swedish: } \rightarrow \text { English: } 86.57 \%\end{array}$ \\
\hline
\end{tabular}




\section{PILOT STUDY}

\section{Purpose}

We chose a prototype Web-based electronic meeting system called Polyglot that allows individuals to exchange comments in any of 80 languages with text automatically translated in 6,320 combinations (e.g., English to Spanish, Spanish to German, etc.) [5]. More languages are available in the current edition of the software than were reported in the study, and additions continue to be made.

The purpose of this study is to evaluate how well a very large group using many languages could function, in a distributed environment. Thus, we sought to recruit as many subjects as possible and use as many of the 80 languages provided by the system as possible. Because no room was large enough, and for the convenience of the subjects, three separate locations were used.

\section{Subjects and Task Description}

We recruited a sample of 66 undergraduate business students (37 males, 29 females) from a university in the southern United States. The group used the electronic meeting software simultaneously, but participants were distributed among three campuses (sizes 35, 15, and 16). They were asked to enter previously prepared foreign comments (the Universal Declaration of Human Rights obtained from www.omniglot.com) into the system to simulate an actual multilingual meeting. That is, each group member copied and pasted the equivalent of "All human beings are born free and equal in dignity and rights. They are endowed with reason and conscience and should act towards one another in a spirit of brotherhood." using one language from the following 66:

Afrikaans, Albanian, Arabic, Armenian, Azerbaijani, Basque, Belarusian, Bengali, Bosnian, Bulgarian, Catalan, Cebuano, Danish, Estonian, Filipino, Finnish, French, Georgian, German, Greek, Gujarati, Haitian Creole, Hausa, Hebrew, Hindi, Hungarian, Icelandic, Igbo, Indonesian, Irish, Italian, Japanese, Javanese, Kannada, Khmer, Lao, Latvian, Lithuanian, Malay, Maltese, Maori, Marathi, Mongolian, Nepali, Norwegian, Persian, Polish, Portuguese, Punjabi, Romanian, Russian, Serbian, Slovak, Spanish, Swahili, Swedish, Tamil, Telugu, Thai, Turkish, Ukrainian, Urdu, Welsh, and Zulu.

The source text was not considered to be very difficult (Flesch Reading Ease $=53.7$ on a scale of $0=$ difficult to $100=$ easy, Flesch-Kincaid Grade Level = 11.2, or high-school level). In addition, the text was chosen because of its potential similarity to information that would be exchanged in an actual, multilingual meeting. All students used the same text, although in different languages, so that judgments of comprehension would be based only upon differences in the ability of the system to translate between other languages and English.

After entering the foreign comments, as shown in Figure 1, the students switched to English to view the group's comments automatically translated by the system. Students were asked what percentage of the comments translated to English they understood, and how much they expected to be able to understand. In addition, they were asked to indicate on a 1-to-7 scale factors related to comprehension, usability, and ease-of-use.

Figure 1. Entering the comment's two sentences in Georgian

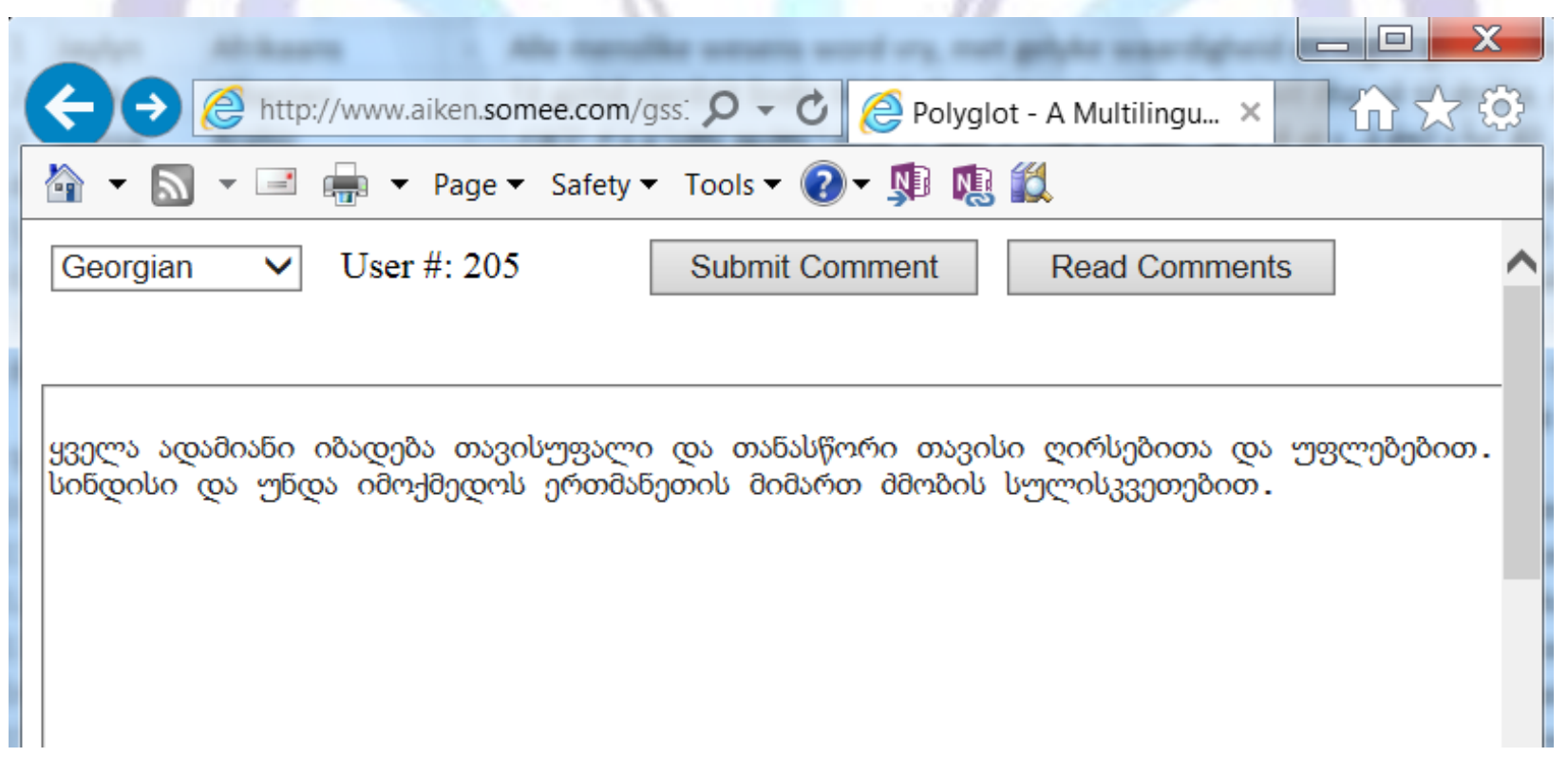

Results 
Many of the translations were verbatim with the stated equivalent English text "All human beings are born free and equal in dignity and rights. They are endowed with reason and conscience and should act towards one another in a spirit of brotherhood." Other translations were nearly identical, e.g., substituting "behave with one another" instead of "act towards one another." Some translations were quite poor, however, including "Cva ljydska pađajy beings are free and equal y dostojanstvy and property rights. She sy obdapena pazymom and sviješćy and shell include the one PPEM dpygome postypajy y DÝHY bpatstva." When the system encountered an unrecognized word, it simply included it in the translation. Only three of the comments were as mangled as that, and a few others had minor problems, e.g. "All human creatures are raǵaat free and equal by dignity and rights. They are endowed with reason and conscience and should behave towards one another in duxot the general čovečkata affiliation."

Consequently, students reported a fairly high rate of comprehension (88.71\%), similar to rates of comprehension found in other studies of systems using other combinations of languages and text, e.g. $78.33 \%$ [10]. Although a little lower, there was no significant difference between this reported rate and the students' stated required rate $(89.85 \%)(t=0.486, p=$ 0.628). In prior studies, required rates of understanding varied from $79.43 \%$ [22] and $80.28 \%$ [19] to $91.12 \%$ [8]. Thus, this measure could be somewhat subjective and based upon differences in group members as well as comment topic and complexity. The required rate reported here is near the high end of those reported earlier.

Table 2 shows summaries of other variables. Students reported understanding English well, understanding the comments, obtaining information from the translations, and believing the translations were accurate. In addition, they believed the meeting system was easy to use and the functionality was clear, and they learned how to use it quickly. Finally, they believed a multilingual meeting would benefit from the system, and they would be willing to use the system in such a meeting.

Table 2. Overall summary of variables

\begin{tabular}{|c|c|c|c|c|}
\hline Variable & Min & Max & Mean* & Std. Dev \\
\hline Comments percentage understood (Actual) & 20 & 100 & 88.71 & 21.449 \\
\hline Comments percentage should understand (Required) & 5 & 100 & 89.85 & 25.825 \\
\hline \multicolumn{5}{|l|}{ Comprehension } \\
\hline 1 I understand English well. & 6 & 7 & 6.91 & .288 \\
\hline 2 I understood the comments translated to English. & 1 & 7 & 6.30 & 1.059 \\
\hline 3 I obtained information from the translated comments. & 2 & 7 & 5.98 & 1.196 \\
\hline $4 \mathrm{I}$ believe the translations were accurate. & 1 & 7 & 5.73 & 1.387 \\
\hline \multicolumn{5}{|l|}{ Ease of Use } \\
\hline 5 The multilingual meeting system was easy to use. & $\beta$ & 7 & 6.18 & 1.066 \\
\hline 6 The functionality of the meeting system was clear. & $\beta$ & 7 & 5.89 & 1.083 \\
\hline 7 I learned how to use the multilingual meeting system quickly. & $\beta$ & 7 & 6.26 & .982 \\
\hline \multicolumn{5}{|l|}{ Usability } \\
\hline $8 \mathrm{I}$ would use this system in a multilingual meeting. & 1 & 7 & 5.76 & 1.290 \\
\hline 9 A multilingual meeting could benefit from this system. & 2 & 7 & 6.26 & 1.057 \\
\hline
\end{tabular}

* All of the mean ratings of comprehension, ease of use, and usability were above the neutral measure of 4.0 at a significance level less than 0.001

Table 3 shows a correlation analysis of the items in the questionnaire, except for self-reported knowledge of English and gender. English skills had no effect on understanding of translations, which is consistent with a prior study of factors influencing comprehension [10]. Also, there were no correlations associated with gender except that females indicated only slightly more a willingness to use the system in a multilingual meeting.

Actual comprehension was highly and significantly correlated with the stated comprehension. However, as students reported both measures only after the study, they might have based one upon the other.

Students who reported understanding a high percentage of the comments naturally stated that they understood the comments. Although this should be evident, the correlation was only 0.50 . They also tended to obtain information from the 
comments and believed the comments were accurately translated. These students believed that the system was easy to use and useful, as well.

\section{CONCLUSION}

\section{Summary}

For the first time, group members distributed among three locations were able to communicate in 66 languages simultaneously and anonymously with translations accurate enough for their expectations. Further, they believed the meeting system was useful and easy to use. We believe that no equivalent oral meeting could function as efficiently and effectively. That is, a verbal discussion would take much more time as participants must take turns speaking, costs would be very high to pay for interpreters for so many languages (many of which are obscure), and comments would need to be manually transcribed. In fact, it might be nearly impossible to conduct such a meeting in a traditional, oral format as interpreters for some languages are not likely to be found easily.

Table 3. Correlation analysis (significant correlations indicated in bold font)

\begin{tabular}{|c|c|c|c|c|c|c|c|c|c|c|c|}
\hline \multirow{3}{*}{ actual } & actual & req & $q 1$ & q2 & q3 & $q 4$ & q5 & q6 & q7 & q8 & $q^{9}$ \\
\hline & 1 & 0.70 & -0.12 & 0.50 & 0.36 & 0.31 & 0.29 & 0.32 & 0.30 & 0.47 & 0.36 \\
\hline & & 0.00 & 0.34 & 0.00 & 0.00 & 0.01 & 0.02 & 0.01 & 0.02 & 0.00 & 0.00 \\
\hline \multirow[t]{2}{*}{ req } & & 1.00 & -0.11 & 0.21 & 0.07 & 0.08 & 0.05 & 0.18 & 0.21 & 0.43 & 0.12 \\
\hline & & & 0.40 & 0.09 & 0.57 & 0.55 & 0.72 & 0.15 & 0.10 & 0.00 & 0.35 \\
\hline \multirow[t]{2}{*}{$q 1$} & & & 1.00 & 0.09 & 0.00 & -0.10 & -0.15 & -0.18 & -0.13 & -0.10 & -0.07 \\
\hline & & & & 0.47 & 0.97 & 0.42 & 0.25 & 0.15 & 0.29 & 0.42 & 0.56 \\
\hline \multirow[t]{2}{*}{ q2 } & & & & 1.00 & 0.50 & 0.32 & 0.25 & 0.35 & 0.28 & 0.32 & 0.22 \\
\hline & & & & & 0.00 & 0.01 & 0.04 & 0.00 & 0.02 & 0.01 & 0.08 \\
\hline \multirow[t]{2}{*}{ q3 } & & & & & 1.00 & 0.47 & 0.41 & 0.47 & 0.53 & 0.41 & 0.50 \\
\hline & & & & & & 0.00 & 0.00 & 0.00 & 0.00 & 0.00 & 0.00 \\
\hline \multirow[t]{2}{*}{$q 4$} & & & & & & 1.00 & 0.59 & 0.47 & 0.50 & 0.34 & 0.54 \\
\hline & & & & & & & 0.00 & 0.00 & 0.00 & 0.01 & 0.00 \\
\hline \multirow[t]{2}{*}{ q5 } & & & & & & & 1.00 & 0.73 & 0.75 & 0.49 & 0.55 \\
\hline & & & & & & & & 0.00 & 0.00 & 0.00 & 0.00 \\
\hline \multirow[t]{2}{*}{$q 6$} & & & & & & & & .00 & 0.82 & 0.57 & 0.54 \\
\hline & & & & & & & & & 0.00 & 0.00 & 0.00 \\
\hline \multirow[t]{2}{*}{ q7 } & & & & & & & & & .00 & 0.66 & 0.56 \\
\hline & & & & & & & & & & 0.00 & 0.00 \\
\hline q8 & & & & & & & & & & 1.00 & 0.63 \\
\hline
\end{tabular}

\section{Limitations}

The study has several limitations. First, it was just a simulation of an actual multilingual meeting. In a real electronic discussion, there would likely be typing errors in source text, significantly decreasing the accuracy of the following translations $[4,20]$. Here, no typing errors were made as text was simply copied from a document provided into the software interface.

Second, as the availability of equivalent text in so many different languages was limited, and only two sentences were used, over and over, the complexity and variety of comments in a real meeting was lacking.

Third, as mentioned earlier, students might be basing part of their stated required understanding rate on their reported actual rate of understanding. The required rate might need to be ascertained before the meeting, rather than at the end.

Fourth, as comments containing the same content were seen many times, students' perception of accuracy might have been changed. If each comment contained different information, students might not have as good an idea what each was about [14]. 


\section{Future Research}

Ideally, studies should use participants typing their own comments in the foreign languages to understand how real multilingual groups work. However, it is difficult to recruit subjects using more than four or five languages, let alone dozens. Thus, we believe simulated meetings with pre-recorded foreign comments might be necessary when focusing on so many tongues. In addition, future research might investigate which of the languages work best together. For example, some studies have shown that translations among Western European languages (e.g., German, Spanish, Dutch, etc.) work very well together [3].

\section{REFERENCES}

[1] Aiken, M. (2000). Brainwriting in virtual legislative sessions. Journal of International Information Management. 9(1), $11-21$.

[2] Aiken, M. (2009). Transterpreting multilingual electronic meetings. International Journal of Management and Information Systems. 13(1), 35-46.

[3] Aiken, M. and Balan, S. (2011). An analysis of Google Translate accuracy. Translation Journal. 16(2).

[4] Aiken, M., Balan, S., Vanjani, M., and Garner, B. (2010). The effect of comment errors in multilingual electronic meetings. Communications of the International Information Management Association. 10(4), 49-60.

[5] Aiken, M. and Ghosh, K. (2009). Automatic translation in multilingual business meetings. Industrial Management \& Data Systems. 109(7), 916-925.

[6] Aiken, M., Martin, J., Paolillo, J., and Shirani, A. (1994). A group decision support system for multilingual groups. Information and Management. 26, 155-161.

[7] Aiken, M. and Park, M., (2009). Machine translation in a multilingual electronic meeting. Journal of International Technology and Information Management. 18(3/4), 395-408.

[8] Aiken, M., Park, M., and Lindblom, T. (2011). A comparison of oral and electronic bilingual meetings. Proceedings of the $42^{\text {nd }}$ Annual Meeting of the Decision Sciences Institute. Boston, MA, November 19-22, 951-956.

[9] Aiken, M., Park, M., and Lindblom, T. (2010) Integrating machine translation with group support systems. International Journal of Business and Management. 5(5), 25-35.

[10] Aiken, M., Park, M., and Lindblom, T. (2013). Language fluency as a factor in machine translation comprehension. International Journal of Computers and Technology. 10(2), 1349-1355.

[11] Aiken, M., Rebman, C., Vanjani, M., and Robbins, T. (2002). Meetings without borders: A multilingual Web-based group support system. America's Conference on Information Systems. August 9-11, Dallas, Texas.

[12] Aiken, M. and Vanjani, M. (1997). A comparison of synchronous and virtual legislative session groups faced with an idea generation task. Information \& Management. 33(1), 25-31.

[13] Aiken, M., Wang, J., Gu, L., and Paolillo, J. (2011). An exploratory study of how technology supports communication in multilingual groups. International Journal of e-Collaboration. 7(1), 17-29.

[14] Aiken, M., Wang, J., Gu, L., and Vanjani, M. (2013). Topic effects on multilingual electronic meeting comprehension. Issues in Information Systems. 14(1), 269-277.

[15] Aiken, M., Wee, J., and Vanjani, M. (2011). A Web-based multilingual meeting system: Breaking the language barrier. Business Research Yearbook. 18(1), 71-76.

[16] Fjermestad, J. and Hiltz, S. (2001). Group support systems: A descriptive evaluation of case and field studies. Journal of Management Information Systems. 17(3), 115-160.

[17] Fügen, C., Waibel, A., and Kolss, M. (2007). Simultaneous translation of lectures and speeches. Machine Translation. 21(4), 209-252.

[18] Jenkins, J. (2007). English as a lingua franca: Attitude and identity. Oxford, UK: Oxford University Press.

[19] Pepper, W., Aiken, M., and Garner, B., (2011). Usefulness and usability of a multilingual electronic meeting system. Global Journal of Computer Science and Technology. 11(10), 35-40.

[20] Shigenobu, T., Fujii, K., and Yoshino, T. (2007). The role of annotation in intercultural communication, 186-195. Aykin, N. (Ed.) Usability and Internationalization: $\mathrm{HCl}$ and Culture. Berlin: Springer.

[21] Vanjani, M. (2012). A review of multilingual electronic meeting research. Business Research Yearbook. 19(1), 126134.

[22] Williams, K., Aiken, M., and Pepper, W. (2012). Multilingual meetings and the time value of accurate translations. Business Research Yearbook. 19(1), 158-165. 


\section{ISSN 2277-3061}

\section{Authors' biographies}

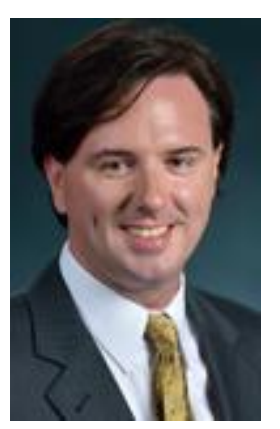

Dr. Jamison Posey is a Clinical Assistant Professor of Management Information Systems in the School of Business Administration at the University of Mississippi. His research interests include machine translation and multilingual meeting systems.

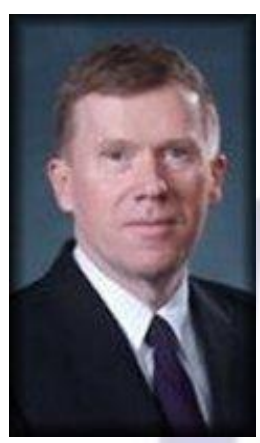

Dr. Milam Aiken is a Professor and Chair of Management Information Systems in the School of Business Administration at the University of Mississippi. His research interests include machine translation and multilingual meeting systems. 